\title{
Differences in Care Use Between Men and Women: The Role of Publicly Financed and Informal Care at Home
}

\author{
ID Debbie Verbeek-Oudijk ID Alice De Boer ${ }^{2}$ ID Isolde Woittiez'
}

\begin{abstract}
Although most recipients of long-term care are women, due to rising life expectancy among men, future users of care are increasingly likely to be men. There are indications that gender is an important factor in the way in which a country organizes its care, and that social policy can have diverging outcomes on the average health of men and women. Nevertheless, gender differences in the use of care are seldom considered. Research into possible explanations for these differences has focused mainly on differences between individual characteristics of men and women. In addition, this study examines the effect of public spending on professional home care and the average availability of informal care by over-50s on the actual use of care. Data from the Survey of Health, Ageing and Retirement 2004, 2007, and 2013 from eight European countries were used, in combination with OECD data on public spending on professional home care. A multinomial regression with fixed effects was estimated for the correlation between these macro characteristics and individual use of care for men and women separately. Findings show that higher public expenditure on home care is associated with less use of paid care, but also that this is particularly the case among men ("paid care" includes care paid for by the user himself or herself). More plentiful informal care is associated with lower use of paid care, in both men and women. One of the possible implications for future policy on long-term care is that men are relatively more likely to respond to changes in the availability of home care than women and that this responsiveness will become even more marked as the proportion of men using care rises.
\end{abstract}

Keywords: Informal care, seniors, gender, home care expenditure

\section{Key Practitioners Message}

> In social policies and the organization of long-term care, gender differences are seldom considered. This study examines the effect of public spending on professional home care and the average availability of informal care by over-50s for men and women separately.

$>$ Higher public expenditure on home care is associated with more use of paid care, particularly among men. More plentiful informal care is associated with lower use of paid care, in both men and women.

$>$ Men are relatively more likely to respond to changes in public spending on home care than women, and this responsiveness will likely become even more marked as the proportion of men using care rises.

\section{Introduction}

Moving forwards, long-term care faces several challenges. For example, the average age of po- pulations will continue to rise as the proportion of older people in the population continues to increase; demand for paid and unpaid forms of long-

\footnotetext{
Correspondence: Debbie Verbeek-Oudijk. P.O. Box 16164, The Hague, Netherlands. e-mail: d.verbeek-oudijk@scp.nl 
term care will therefore also rise. Additionally, more older people prefer to be cared for in their own home for as long as possible (OECD 2017). All these developments will affect not only the affordability of care but also the supply of care. Currently, most recipients of long-term care are women (Colombo et al. 2011). For many years women have had a higher life expectancy than men. However, the difference in life expectancy is decreasing, which means that in the future long-term users of care are increasingly likely to be men.

Gender differences in the use of care have been investigated many times, and women generally receive more long-term care than men (Dorin, Krupa, Metzing, \& Beuscher, 2016; Enroth, Aaltonen, Raitanen, Nosraty, \& Jylhä, 2018; Grundy \& Jitlal, 2007; Katz, Kabeto M., \& K.M., 2000; Luppa M. et al., 2010; Martikainen P., Murphy, Metsä-Simola, Häkkinen, \& Moustgaard, 2012; Schmidt, 2018). The explanations often focus on age and health. Globally, life expectancy is higher for women than for men, and the decline in mortality is lower for men than for women across all age groups (Wang et al., 2012). Furthermore, women, regardless of their average age, also seem to report poor health significantly more often than men (Boerma, Hosseinpor, Verdes, \& Chatterji, 2016), despite the fact that morbidity for many disorders is higher in men (Hawkes S. \& Buse, 2013).

In addition to these types of individual characteristics, other determinants have also been mentioned in order to account for the gender-specific use of care. This includes social determinants, such as network characteristics, and financial resources; determinants often used in the explanation of care use (Babitsch, Gohl, \& von Lengerke, 2012; Von Lengerke, Gohl, \& Babitsch, 2014).

Research shows that most of the long-term care is provided by informal caregivers (Chiatti et al., 2013), especially by the women in a family (Bond et al., 1999; Litwak, 1985; Silverstein, Gans, \& Yang, 2006). At least two developments are underway in social networks and the informal help that these can provide. First, the relationship between family and non-family care is changing. Several studies have shown that non-kin make up a rising proportion of social networks for later birth cohorts (Suanet \& Antonucci, 2017; Suanet, Broese van Groenou, \& van Tilburg, 2017). Suanet and Antonucci (2017) assume that these changes in social networks will have a particular effect on women in the future. They anticipate that women's networks will include more (ex-) colleagues and non-kin as a result of women's increasing labor force participation. Research shows, however, that non-kin are less likely to provide informal care than family members (Barker, 2002; Jacobs, Broese van Groenou, Aartsen, \& Deeg, 2018). Secondly, employment participation rates among women have increased over recent decades, which means that the time they have available for providing informal care may be decreasing. Although there is no oneon-one relationship between informal care provision and paid work, there are indications that it has become more difficult for older persons to receive informal care from adult daughters or other family members (Haberkern, Schmid, \& Szydlik, 2015).

Furthermore, men seem to ask for and accept professional care less often because they are expected to solve their own care problems; an image that is reinforced through social interactions (Pattyn, Verhaeghe, \& Bracke, 2015; Verbrugge, 1985). For example, Pattyn, Verhaeghe, and Bracke (2015) show in a vignette study that both men and women were more likely to advise men to look after themselves, and they considered therapy less effective for men. Other research shows that husbands are less likely to provide care for their wives than vice versa, possibly because women tend to be seen as more suitable carers, having the right skills, or believing that they have them (Schenk, Dykstra, Maas, \& Van Gaalen, 2014). Men, therefore, tend to prefer informal care (Pinquart \& Sörensen, 2002) and receive informal care from their partners more often than women do (Glauber, 2017; Schenk, Dykstra, Maas \& Van Gaalen, 2014). 
Financial resources also play a role in gender differences in the use of care. Lower-income groups generally receive more long-term care (Nihtilä \& Martikainen, 2007). On the other hand, higher-income groups have more opportunities to purchase care (Broese van Groenou, Glaser, Tomassini, \& Jacobs, 2006; Puthenparambil, Kröger, \& Van Aerschot, 2017). The income of older men is generally higher than that of older women, although this difference is becoming less pronounced (OECD, 2011). The financial knowledge and skills of women also lag behind those of men, which means that they are less likely to have made financial preparations for their future (Bucher-Koenen, Lusardi, Alessie, \& Van Rooij, 2017). Higher-income groups are also more willing to pay for care than those with lower incomes (Nieboer, Koolman, \& Stolk, 2010). Because of their higher income, men are more likely to be able to afford to purchase care, while women are more likely to use publicly funded care.

The role of the organization of care and policy on care use are also cited as explanations for care usage patterns (Hlebec \& Filipovic Hrast, 2016; Suanet, Broese Van Groenou, \& Van Tilburg, 2012; Verbeek-Oudijk, Woittiez, Eggink, \& Putman, 2014). For instance, the use of paid care is higher in countries where the responsibility for long-term care lies mainly with the government (Verbeek-Oudijk et al. 2014). The availability of social care services (only available in the morning vs. throughout the day) and the total number of users of these services also appears to be a second important predictor of whether formal and informal care is received (Hlebec \& Filipovic Hrast, 2016). Comparable results were obtained by Suanet, Broese Van Groenou and Van Tilburg (2012), who show that in countries with fewer home care services, less institutional care and more informal care, older people are more likely to rely on informal care alone. These studies did not look at the differences between men and women. Although earlier research has found that no unequivocal conclusions can be drawn about the link between formal and informal care
(Pickard, Wittenberg, Comas-Herrera, Davies, \& Darton, 2000), the study by Suanet, Broese van Groenou and Van Tilburg (2012), like many other studies (Bolin, Lindgren, \& Lundborg, 2008; Gannon \& Davin, 2010; Hanaoka \& Norton, 2008; Kemper, 1992; Van Houtven \& Norton, 2004) would suggest that informal and formal care are substitutes for one another. A similar line of reasoning can be used in relation to care that is paid for by the recipient and publicly-funded care: one form of care provides an alternative to the other.

The combination of gender differences with the use of formal/informal care and care provision has seldom been investigated, however. There are indications that gender is an important factor in the way in which countries organize care. For example, (Saraceno \& Keck, 2011) state that, although it is formulated as gender-neutral, care policy is in fact rarely gender-neutral. Beckfield (2017) described how the indicators of social policy have different outcomes on the average health of men and women. However, there is ambiguity about the direction of the relationship; some types of investment predominantly benefit men and others predominantly benefit women. If social investment influences the health of men and women in different ways, it is plausible that the same may apply to their use of care. Morgan et al. (2016) state that too little account is taken of differences between men and women in the provision of care. They argue that gender affects needs, perceptions, and outcomes across all facets of the health system. In addition, they observe that social expectations dictate what men and women "ought to do", and that these influence the way in which people live, work and relate to one another in multiple areas of life, including health and care. In their view, gender influences health, choices, and behaviors, and thus it affects not only the demand for care but also the decision to use care and what type of care is required or desirable. These assumptions have not been tested empirically, however. 
It can be concluded from the literature that women use care because they tend to experience poorer health and have lower socioeconomic status. In addition, women tend to be more forthcoming in asking for professional care. They are therefore more likely to be sensitive to the availability of care. If spending on publicly funded care increases, women are more likely to use this care and less likely to receive informal care or paid care. Because men are relatively more likely to receive care from their partner, men will rely more on informal care. The expectation is that a high level of informal care in a country is associated with more use of informal care, especially among men. The following hypotheses are formulated:

Hypothesis 1: Higher levels of public spending on professional home care are associated with lower use of informal care and care paid for by the user, especially among women

Hypothesis 2: Higher levels of informal care provision in a country are associated with higher use of informal care and lower use of care paid for by the user, especially among men.

\section{Materials}

In order to accurately estimate the relationship between macro characteristics, on the one hand, and the use of care on the other, data is used from a longitudinal database: The Survey of Health, Ageing and Retirement in Europe (Börsch-Supan, Jürges, \& Lipps, 2003). Eight countries and three years were selected: 2004, 2007, and 2013. The effect of public spending on professional home care on the individual use of care is estimated with a multinomial logit with fixed effects. The longitudinal nature of the data and analysis helped isolate the relationship of interest, although the relationships cannot be interpreted as causal, as explained later. Fixed effects analysis in this study automatically select the respondents who used care in the first year they participated and no longer use care in later years, respondents who didn't use care before but do in later years and respondents who used informal care and switched to paid care or vice versa. Therefore, the data concerns over-50s who participated in the SHARE survey at least twice, and whose use of care changed during the research period.

\section{Participants}

Overall, this study includes 16,458 observations of 6,471 respondents who participated in either two or three measurement years of the SHARE survey. The respondents were 67 years old on average in 2004 ranging from 50 to as old as 104 years. In 2007 the average age was slightly higher (68 years) and was the highest in 2013 (73 years). Most of the respondents were female $(60 \%$ in 2004 and 2007 and 63\% in 2013). 36\% had moderate or serious physical limitations in 2004 compared to $44 \%$ in $2013 ; 17 \%$ dealt with moderate or serious depressive feelings in 2004 compared to $20 \%$ in 2013 . A relatively large share of the respondents is Belgian (about 20\%) and a relatively small share is Swiss (about 5\%). Weighted data are used to adjust for these differences. For a complete overview of the descriptive statistics, see Table-1 and Table-2.

Table-1. Descriptive statistics (means \& standard deviations) of the research population, by year

\begin{tabular}{lrrr}
\hline Variable & 2004 & 2007 & 2013 \\
\hline Age & $68.53(10.98)$ & $67.62(11.04)$ & $73.33(9.64)$ \\
Chronic & $1.57(1.4)$ & $1.56(1.42)$ & $1.85(1.5)$ \\
conditions & & & \\
\hline
\end{tabular}

Note. Values in parentheses indicate standard deviations.

\section{Macro Data}

For this study, national datasets were used to explain the use of care. The first of these was registration data on public spending on home care, which includes the bulk of expenditure on long-term care (Colombo, Llena-Nozal, Mercier, \& Tjadens, 2011; Grabowski, Norton, \& Van Houtven, 2012). This is government spending 
on professional home care ${ }^{1}$ which is recorded by the OECD and divided into "healthcare" and "social care". The former relates to, among other things, personal care and nursing care, and the latter includes domestic help and support. However, countries differ in which spending they

Table-2. Descriptive statistics of the research population (continued), by year

\begin{tabular}{|c|c|c|c|}
\hline & \multicolumn{3}{|c|}{$N(\%)$} \\
\hline & 2004 & 2007 & 2013 \\
\hline \multicolumn{4}{|l|}{ Gender } \\
\hline Man & $2111(40 \%)$ & $2216(40 \%)$ & $1666(37 \%$ \\
\hline Woman & $3184(60 \%)$ & $3335(60 \%)$ & $2880(63 \%$ \\
\hline \multicolumn{4}{|l|}{ Physical limitations } \\
\hline None & $2001(38 \%)$ & $2266(41 \%)$ & $1465(32 \%$ \\
\hline Slight & $1436(27 \%)$ & $1304(24 \%)$ & $1059(23 \%$ \\
\hline Moderate & $1196(23 \%)$ & $1226(22 \%)$ & $1051(23 \%$ \\
\hline Serious & $662(13 \%)$ & $755(14 \%)$ & $972(21 \%)$ \\
\hline \multicolumn{4}{|l|}{ Depressive feelings } \\
\hline None & $3661(69 \%)$ & $3843(69 \%)$ & $3002(66 \%$ \\
\hline Slight & $746(14 \%)$ & $779(14 \%)$ & $675(15 \%)$ \\
\hline Moderate & $477(9 \%)$ & $486(9 \%)$ & $437(10 \%)$ \\
\hline Serious & $411(8 \%)$ & $443(8 \%)$ & $433(10 \%)$ \\
\hline \multicolumn{4}{|l|}{ Partner } \\
\hline No & $2163(41 \%)$ & $2325(42 \%)$ & $2088(46 \%$ \\
\hline Yes & $3132(59 \%)$ & $3227(58 \%)$ & $2458(54 \%$ \\
\hline \multicolumn{4}{|c|}{ Child $>17$ years in the household } \\
\hline No & 4792 (91\%) & $5128(92 \%)$ & $4090(90 \%$ \\
\hline Yes & $503(10 \%)$ & $424(8 \%)$ & 457 (10\%) \\
\hline \multicolumn{4}{|l|}{ Income quartile } \\
\hline 1 & 1525 (29\%) & 1577 (28\%) & 1587 (35\% \\
\hline 2 & 1405 (27\%) & 1591 (29\%) & 1371 (30\% \\
\hline 3 & $1258(24 \%)$ & $1264(23 \%)$ & 915 (20\%) \\
\hline 4 & $1108(21 \%)$ & $1120(20 \%)$ & $673(15 \%)$ \\
\hline \multicolumn{4}{|l|}{ Country } \\
\hline Austria & $493(9 \%)$ & 447 (8\%) & $274(6 \%)$ \\
\hline Germany & $638(12 \%)$ & $676(12 \%)$ & 429 (9\%) \\
\hline The Netherlands & $729(14 \%)$ & 735 (13\%) & 541 (12\%) \\
\hline Spain & $681(13 \%)$ & $660(12 \%)$ & 955 (21\%) \\
\hline France & 805 (15\%) & 844 (15\%) & 595 (13\%) \\
\hline Denmark & $553(10 \%)$ & 763 (14\%) & 655 (14\%) \\
\hline Switzerland & $220(4 \%)$ & $313(6 \%)$ & $256(6 \%)$ \\
\hline Belgium & $1177(22 \%)$ & $1112(20 \%)$ & 842 (19\%) \\
\hline
\end{tabular}

1 To improve readability the term home care instead of professional home care is used. define as healthcare and which as social care. To minimize the effect of any differences in these definitions between countries, both types of spending were combined. Overall spending also fits better with the evaluation of individual care use in SHARE, which includes both personal care as well as household care. Expenditure is measured as a percentage of gross domestic product (GDP); this is the best available indicator for the countries and the research period that this study focuses on. Spending on home care as a percentage of GDP describes the relative importance that the government accords to home care compared to other publicly funded services.

The supply of informal care is not available in the registration data. However, the SHARE data also makes it possible to aggregate data on informal care at the country level. There is no generally accepted definition of informal care (Roth, Fredman, \& Haley, 2015). For the purpose of this study, the definition was based on the questions in the SHARE survey. A person provides informal care if he/she provides personal care to someone in their own household and/or provides support in the form of household or personal care to someone outside their own household. Care within the same household is a help that is provided daily. For care outside of the household, it was asked how often care is given: occasionally, monthly, weekly or daily. For each of the respondents, aged 50 years or above, it is known whether they provide informal care and whether that care is occasional or regular. This information was used to create a measure for the provision of informal care, as well as the frequency of the care provided. The starting point was a discrete variable that takes the value 0 if no informal care is provided, the value 1 if care is provided monthly or less frequently, and the value 2 if it is weekly or daily. The average for each country and each year was calculated. The change in the average thus reflected the change in the supply of informal caregiving among over-50s in a country. Table-3 provides an overview of the national data that were included in this study. ${ }^{2}$

2 The 2015 OECD data on public spending on home care were obtain from stats.oecd.org; Health expenditure and financing - Long-term nursing care: home care. 
Table-3. Summary of public spending on home care and average supply of informal care for the over-50s in eight European countries, by year

\begin{tabular}{|c|c|c|c|c|c|c|}
\hline & \multicolumn{3}{|c|}{$\begin{array}{c}\text { Public Spending on } \\
\text { Home Care } \\
\text { (\% GDP) }\end{array}$} & \multicolumn{3}{|c|}{$\begin{array}{c}\text { Average Supply of } \\
\text { Informal Care } \\
(0-2)\end{array}$} \\
\hline & 2004 & 2007 & 2013 & 2004 & 2007 & 2013 \\
\hline Austria & $.67 \%$ & $.66 \%$ & $.74 \%$ & .44 & .51 & .39 \\
\hline Belgium & $.56 \%$ & $.59 \%$ & $.80 \%$ & .74 & .71 & .54 \\
\hline Denmark & $1.05 \%$ & $1.12 \%$ & $1.22 \%$ & .68 & .66 & .56 \\
\hline Germany & $.71 \%$ & $.78 \%$ & $.96 \%$ & .53 & .58 & .45 \\
\hline France & $.42 \%$ & $.39 \%$ & $.49 \%$ & .49 & .48 & .43 \\
\hline $\begin{array}{l}\text { The } \\
\text { Netherlands }\end{array}$ & $1.47 \%$ & $1.48 \%$ & $1.82 \%$ & .66 & .68 & .51 \\
\hline Spain & $.14 \%$ & $.17 \%$ & $.22 \%$ & .36 & .35 & .29 \\
\hline Switzerland & $.47 \%$ & $.49 \%$ & $.55 \%$ & .58 & .52 & .37 \\
\hline $\begin{array}{l}\text { Unweighted } \\
\text { Average }\end{array}$ & $.69 \%$ & $.71 \%$ & $.85 \%$ & .56 & .56 & .44 \\
\hline
\end{tabular}

Note: Definition supply of informal care: $0=$ provides no informal care; 1 = provides occasional or monthly informal care; 2 = provides weekly or daily informal care.

A face-value comparison shows that the share of public spending on home care increased in all countries between 2004 and 2013. By contrast, the degree to which informal care was provided in these countries decreased everywhere and was significantly lower in 2013 than nine years earlier. Public spending on home care is particularly high in Denmark and the Netherlands, and lower in Spain and Switzerland. It is also remarkable that the extent to which informal care is provided is also relatively high in Denmark and the Netherlands and lower in Spain and Switzerland.

\section{Micro Data}

The source for the individual data was the Survey of Health, Ageing, and Retirement in Europe (Börsch-Supan, Jürges \& Lipps, 2003). The data concerned people aged over 50 living independently in various European countries. SHARE is a longitudinal survey. The survey was carried out for the first time in 2004 and repeated in 2007, 2011 and 2013. Respondents from eight European countries were selected - Austria, Belgium, Denmark, France, Germany, the Netherlands, Spain, and Switzerland - who had participated in the survey at least twice in 2004, 2007 or 2013 and for whom a change in the use of care had occurred. ${ }^{3}$ As explained previously, longitudinal nature of the data was used in order to better estimate the relationship between macro characteristics and the use of care. The focus is on changes over time and not on differences between individuals. The method (see description of the statistic method) thus only included those characteristics that changed over time.

The dependent variable of interest in this study was the use of care. A discrete variable was created to which three values could be assigned (no care, informal care, and paid care). ${ }^{4}$ The definition of informal care and paid care was based on the questions included in the SHARE survey. A respondent received informal care if he/she received personal care and support from someone in their own household and/or received support in the form of household or personal care from someone outside their own household. Paid care was defined as the use of professional or paid care services at home due to physical, mental, emotional or memory problems. Unfortunately, user-paid and publicly-funded care cannot be differentiated. It is probable that the relationship between public spending on home care and the individual use of home care is different from that between user-spending and paid care. After all, these forms of care are substitutes for one another.

In 2004, $20 \%$ of men aged 50 and older received care in these eight European countries; $14 \%$ received informal care and $6 \%$ paid care, possibly including informal care (Table-4). The share of men receiving informal care fell by 4 percentage points to $10 \%$ in 2013 . The share of men receiving paid care increased less rapidly, by only 1 percentage point. The use of care was higher among women over-50. $30 \%$ of women received care; two-thirds of these received informal care and one-third received paid care. The difference in the use of care between men and women hardly changed in the period 2004-2013, although the share of users of informal care fell slightly.

3 The 2011 measurement was not included because that survey did not include questions about the receipt of paid care.

4 The number of observations did not allow the combination of paid and informal care to be differentiated from paid care alone. For this reason, these two groups are combined in the category of paid care. 
Table-4. Use of informal and paid care among over-50s in eight European countries, by year and gender

\begin{tabular}{ccccccc}
\hline & \multicolumn{2}{c}{ No care } & \multicolumn{2}{c}{ Informal care } & \multicolumn{2}{c}{ Paid care } \\
& Men & Women & Men & Women & Men & Women \\
\hline 2004 & $80 \%$ & $70 \%$ & $14 \%$ & $19 \%$ & $6 \%$ & $11 \%$ \\
2007 & $82 \%$ & $71 \%$ & $13 \%$ & $19 \%$ & $5 \%$ & $10 \%$ \\
2013 & $83 \%$ & $73 \%$ & $10 \%$ & $13 \%$ & $7 \%$ & $14 \%$ \\
\hline
\end{tabular}

In addition to the macro characteristics, several explanatory variables for the use of care were included, as outlined earlier. Three health characteristics were included that described the care needs of the respondent. First, the degree of physical limitation (0-3) was defined as no, slight, moderate and serious limitations. A similar categorization was used in relation to signs of depression, the second health characteristic that was included. Finally, the number of chronic health conditions that the respondent was living with were counted. The number varied between 0 and 8 conditions. The method used to construct the hierarchical scales for physical limitations and depression was developed by (Mokken, 1971). The scale for the physical limitations was an indication of the extent to which respondents have difficulty carrying out a selection of 22 daily activities. The score for indicators of depression was based on feelings of sadness, fatigue, poor sleep, reduced appetite, lack of interest in surroundings and feelings of no longer wanting to live. The construction of both scales has been described extensively (Oudijk, Woittiez, \& de Boer, 2011; Verbeek-Oudijk et al., 2014) and has been applied (Plaisier, Verbeek-Oudijk, \& De Klerk, 2016).

Social and economic sources are another important explanatory variable for the use of care (Babitsch, Gohl, \& von Lengerke, 2012; Von Lenkerke, Gohl, \& Babitsch, 2014). A large proportion of informal care comes from partners and adult children (Tarricone \& Tsouros, 2008; Triantafillou et al., 2011). Therefore, the presence of a partner (yes/no) and adult children within the household (yes/no) are included in the analyses. Because income was measured in a different way in 2007 and was consistently lower in that year compared to in other years, income amount could not be included. As an alternative, income quartiles were used as a proxy for financial resources.

Finally, a dummy for "year" was included as an explanatory variable, because the macro variables are country-specific variables that vary over time. If the analyses were not corrected for time separately, general shocks may have rendered the effect of macro variables less clearly visible over time. One example is the economic crisis that occurred in 2008, which may have impacted on spending on home care.

\section{Method}

The relationship between the macro characteristics and individual use of care is estimated separately for men and women, correcting for the micro-characteristics mentioned previously by using multinomial logistic regression with fixed effects, as developed by Chamberlain (1980) and implemented by Pforr (2014) in Stata. The method was developed for longitudinal data and controls for the effects of unmeasured variables that may have influenced the relationship between the macro characteristics on the one hand and the use of care on the other, which may have led to inconsistent estimates. An example of such unmeasured variables is individual personality traits. For example, an assertive individual would be likely to seek a solution to their care problem more quickly than a person who is more reserved. In a regression without fixed effects, the degree of assertiveness could then have a distorting effect on the relationships between spending on care and use of care. Fixed effects analyses focus on variations in individuals, or on variations over time, and not on variation between individuals. The models control for time-invariant unobserved heterogeneity (Gangl, 2010). The assumption here was that the unmeasured variables would remain constant over time.

The macro characteristics included in the model were country-specific variables that varied over time, which means that the variables have the same value for all individuals in a country in a given year. Individuals are clustered within countries, which could have influenced the correlation between the macro characteristics and the individual's use 
of care. The standard error was adjusted by using the Huber-White Sandwich Estimator to control for clustering within countries. The model included two country-specific variables that varied over time. The reliability of the results could have been undermined if the correlation between the variables was too high. In contrast to other regression analyses, there is no standard multicollinearity test in fixed effects analyses. To gain some understanding of the mutual correlation, the Cronbach's alpha was calculated. The reliability of the association, which was 0.4 , did not appear to be too high. Additional$l y$, as a sensitivity analysis, the macro variables were added one by one to see if the coefficients were stable and did not change too much. There was, therefore, no indication of multicollinearity in the analyses. ${ }^{5}$ Whether the relationship between the macro characteristics and the use of care among men differed significantly from that among women was assessed in two ways. First, $Z$ scores were calculated: $\left.\left(\mathrm{B}_{\text {woman }}-\mathrm{B}_{\text {man }}\right) / \sqrt{(} \mathrm{SE}_{\text {woman }}{ }^{2}+\mathrm{SE}_{\text {man }}{ }^{2}\right)$ (Paternoster, Brame, Mazerolle, \& Piquero, 1998). In addition, a model was estimated for men and women together, in which interaction terms with gender for all macro and individual characteristics were included. Because the effects of the macro characteristics are the primary interest of this study, only these interaction terms are shown. To get an idea of the effect of the level of public expenditure on home care and the average supply of informal care among people over 50 , the average (semi) elasticity was calculated using the Stata module aextlogit (Kemp \& Santos Silva, 2016). The coefficients can be interpreted as "when expenditure is increased by e.g. one unit, the average chance that care is received increases by $x \%$. 6

There are two possible endogenous issues in the use of panel data that need to be addressed: omitted variable bias and reverse causality. Macro attributes at the country level may unintentionally reflect the effects of other variables that vary over time. In such cases, there is omitted variable bias.

5 The same also applies to the other explanatory variables. The direction and order of magnitude of the coefficients were very stable.

6 The basic estimate of the aextlogit is a conditional logit and it therefore deviates from the multinomial logit with fixed effects, which is central to this article. This means the likelihood of paid care vs. no care and the likelihood of informal care vs. no care were estimated. The results of the conditional logit did not deviate greatly.
To correct for this, a dummy for "year" in is included in the model that controlled for general shocks, such as the economic recession of 2008 which affected care spending and possibly informal caregiving. Reverse causality implies that causality also runs in the opposite direction. The macro variables in the analyses are related to the individual use of care. It is plausible that changes in the use of care at the individual level also affected the macro variables in the analyses, but the effect would have been delayed. The countries included in the study use (varying degrees of) budgeted LTC systems with access criteria. As such, undesirable developments in the individual use of care often lead to changes to the access criteria, which ultimately lead to a change in expenditure on care. Nevertheless, reverse causality cannot be ruled out and it is appropriate to exercise caution when it comes to attributing causality. For this reason, this study speaks of correlation rather than causation.

\section{Results}

The relationship between the macro characteristics and the individual use of care differs between men and women. Public expenditure on home care is negatively correlated with the likelihood of receiving informal care, but only among men ( $\beta=-2.46$, Table-5). For both men $(\beta=-6.97)$ and women ( $\beta$ $=-3.29$ ), public expenditure on home care is also associated with a lower likelihood of the use of paid care. As mentioned previously, unfortunately, it was not possible to distinguish between publicly funded home care and care paid for by the user. However, the negative association found between public expenditure on home care and paid care would suggest that most of the paid care reported in the survey was care paid for by the user.

The proportion of informal carers aged 50 or older in a country does not correlate significantly with informal care received but is negatively associated with the receipt of paid care (men, $\beta=$ -12.12, women, $\beta=-6.92$ ). The absence of any association with informal care could be explained if the increase in the supply of care mainly results in more hours of care being received rather than more people receiving care. Alternatively, and 
conversely, it could be explained if a decrease in the supply of informal care, as shown in Table-3, mainly results in a decrease in the number of care hours provided. Additionally, some of the care will also be provided by those aged below 50 years. Unfortunately, the data did have information on under 50 -s. women when a partner or adult child is present. This is probably because these women are often younger and are less likely to receive care from their partner. Among men, there is a significant relationship between income quartile and the informal use of care. The likelihood of receiving informal care is higher in the higher income quartiles than in the lower income quartiles, although

Table-5. Multinomial logical regression with individual fixed effects of the use of informal and paid care by over-50s in eight European countries, by gender

\begin{tabular}{|c|c|c|c|c|}
\hline & \multicolumn{2}{|c|}{ MEN } & \multicolumn{2}{|c|}{ WOMEN } \\
\hline & Informal Care & Paid Care & Informal Care & Paid Care \\
\hline & $\beta(95 \mathrm{Cl})$ & $\beta(95 \mathrm{Cl})$ & $\beta(95 \mathrm{Cl})$ & $\beta(95 \mathrm{Cl})$ \\
\hline Public spending on home care & $-2.46(-4.03 \text { to }-.90)^{* *}$ & $-6.97(-9.17 \text { to }-4.77)^{* * *}$ & $-.41(-1.64$ to .83$)$ & $-3.29(-4.80 \text { to }-1.88)^{* * *}$ \\
\hline $\begin{array}{l}\text { Proportion of informal carers } \\
\text { aged } 50 \text { years and older } \\
\text { Physical limitations }\end{array}$ & $.40(-2.27$ to 3.07$)$ & $-12.12(-15.64 \text { to }-8.60)^{* * *}$ & $1.71(-.43$ to 3.85$)$ & $-6.92(-9.41 \text { to }-4.43)^{* * *}$ \\
\hline Slight & $.80(.60 \text { to } 1.01)^{* * *}$ & $.81(.50 \text { to } 1.11)^{* * *}$ & $.56(.40 \text { to } .71)^{* * *}$ & $.78(.53 \text { to } 1.02)^{* * *}$ \\
\hline Moderate & $1.31(1.06 \text { to } 1.56)^{* * *}$ & $1.65(1.30 \text { to } 2.01)^{* * *}$ & $1.02(.82 \text { to } 1.21)^{* * *}$ & $1.43(1.18 \text { to } 1.69)^{* * *}$ \\
\hline Serious & $2.61(2.22 \text { to } 2.99)^{* * *}$ & $2.64(2.22 \text { to } 3.06)^{* * *}$ & $2.06(1.79 \text { to } 2.33)^{* * *}$ & $2.71(2.38 \text { to } 3.03)^{* * *}$ \\
\hline \multicolumn{5}{|l|}{ Depressive feelings } \\
\hline Slight & $.28(.03 \text { to } .54)^{*}$ & $.64(.28 \text { to } 1.00)^{* * *}$ & $.28(.11 \text { to } .45)^{* *}$ & $.55(.33 \text { to } .77)^{* * *}$ \\
\hline Moderate & $.49(.12 \text { to } .87)^{* *}$ & $.68(.21 \text { to } 1.14)^{* *}$ & $.55(.34 \text { to } .76)^{* * *}$ & $.69(.42 \text { to } .95)^{* * *}$ \\
\hline Serious & $1.02(.58 \text { to } 1.46)^{* * *}$ & $1.31(.82 \text { to } 1.81)^{* * *}$ & $.57(.33 \text { to } .82)^{* * *}$ & $.85(.55 \text { to } 1.14)^{* * *}$ \\
\hline Number of chronic conditions & $.11(.03 \text { to } .18)^{* *}$ & $.37(.26 \text { to } .47)^{* * *}$ & $.15(.10 \text { to } .21)^{* * *}$ & $.18(.12 \text { to } .25)^{* * *}$ \\
\hline \multicolumn{5}{|l|}{ Household situation } \\
\hline Partner present & $-.20(-.53$ to .12$)$ & $-.20(-.63$ to .23$)$ & $-.52(-.79 \text { to } .25)^{* * *}$ & $-.18(-.53$ to .16$)$ \\
\hline Child $>17$ years in household & $-.17(-.49$ to .14$)$ & $-.47(-.96$ to .02$)$ & $-.30(-.58 \text { to } .04)^{*}$ & $-.19(-.59$ to .21$)$ \\
\hline \multicolumn{5}{|l|}{ Income quartile } \\
\hline Second quartile & $.44(.22 \text { to } .66)^{* * *}$ & $.13(-.18$ to .44$)$ & $.12(-.04$ to .28$)$ & .16 (-.03 to .37$)$ \\
\hline Third quartile & $.35(.10 \text { to } .60)^{* *}$ & $.06(-.28$ to .41$)$ & $.04(-.15$ to .23$)$ & $.17(-.08$ to .42$)$ \\
\hline Fourth quartile & $.36(.11 \text { to } .62)^{* *}$ & $-.05(-.43$ to .33$)$ & $.02(-.18$ to .24$)$ & -.15 (-.43 to .13$)$ \\
\hline \multicolumn{5}{|l|}{ Year } \\
\hline 2007 & $-.06(-.19 \text { to } .07)^{* * *}$ & $.31(.10 \text { to } .51)^{* *}$ & $.00(-.11$ to .11$)$ & $.18(.02 \text { to } .33)^{*}$ \\
\hline 2013 & .15 (-..17 to .47$)$ & $.68(.20 \text { to } 1.16)^{* *}$ & -.05 (-..31 to .21$)$ & $.73(.38 \text { to } 1.08)^{* * *}$ \\
\hline Pseudo R2 & .21 & & .19 & \\
\hline
\end{tabular}

Note 1: Huber-White sandwich estimator used for heteroscedasticity-consistent standard errors.

Note 2: Reference categories are: no physical limitations, no depressive feelings, no partner present, no child older than 17 years present, first income quartile and 2004.

Note 3: Notation of significance level: ${ }^{\star} p<0.05,{ }^{\star \star} p<0.01,{ }^{\star \star \star} p<0.001$

There are remarkable differences between men and women in terms of individual characteristics. The presence of a partner and adult children in the household is significantly negatively correlated with the use of informal care among women but plays no role in this among men. The likelihood of receiving informal care is lower for this effect becomes less pronounced as incomes increase. The average age is generally higher in the lower-income groups. As age increases, the size of the social network shrinks and those who remain often also face health problems themselves, which can affect their ability to provide informal care. 
The differences between men and women in the effect of the macro characteristics on the use of care are subsequently tested for significance in two ways; a Z-test and interaction terms. The differences between men and women described above remained valid in all cases (Table-6). and who therefore used more care; however, the difference in life expectancy between men and women, and therefore the differing demand for care, will decrease steadily in the future. The provision of care will need to respond to this change. This article helps to determine to what extent

Table-6. Tests for differences in effects of macro characteristics on use of informal and paid care between men (Z-score and interaction terms)

\begin{tabular}{lcccc}
\hline & \multicolumn{2}{c}{ Ztest } & Interaction Terms \\
& $\begin{array}{c}\text { Informal } \\
\text { Care }\end{array}$ & Paid Care & Informal Care & Paid Care \\
& $\mathrm{Z}_{\mathrm{M}-\mathrm{w}}$ & $\mathrm{Z}_{\mathrm{M}-\mathrm{w}}$ & $\mathrm{B}_{\mathrm{M}^{*} \text { macrocharacteristic }}(95 \mathrm{Cl})$ & $\mathrm{B}_{\mathrm{M}^{*} \text { macrocharacteristic }}(95 \mathrm{Cl})$ \\
\hline Public spending on home care & $\mathbf{2 . 0 1}$ & $\mathbf{2 . 7 1}$ & $-2.60(-4.16 \text { to }-1.05)^{* *}$ & $-6.71\left(-8.90\right.$ to $-4.511^{* * *}$ \\
Proportion of informal carers aged 50 years and older & .75 & $\mathbf{2 . 3 6}$ & $-.30(-2.77$ to 2.16$)$ & $-11.40(-14.69 \text { to }-8.10)^{* * *}$ \\
\hline Note-1: Interaction term calculated using a multinomial logistic regression in which all macro and individual characteristics are \\
interacted with gender. \\
Note-2: Notation of significance level; Z-score $>1.96$ in bold, interaction term * $\mathrm{p}<.05,{ }^{* *} \mathrm{p}<.01,{ }^{* * *} \mathrm{p}<.001$
\end{tabular}

To get an idea of the strength of the relationships found here, the (semi-) elasticity is determined. ${ }^{7}$ When public spending on home care increases by one unit, the average likelihood of men receiving paid care decreases by $7.0 \%(p<0.001)$ and the likelihood of men receiving informal care decreases by $1.9 \%(p<0.01)$. For women, there is only a significant relationship for the use of paid care, which is considerably lower, with an average decrease of $3.2 \%(p<0.001)$. The (semi-) elasticity of the average supply of informal care was also calculated. When the supply of informal care increases by one unit, the likelihood of men receiving paid care decreases by $11.8 \%$. The association between both spending on home care and the average supply of informal care is, therefore, greater for men than for women. These results suggest that men are likely to respond more strongly to the supply of (informal and paid) care than women, for whom the use of care is influenced more by individual characteristics.

\section{Discussion}

Given the increasing number of older people and increasing life expectancy, the use of long-term care will increase in the years to come. In the past, it was mainly the women who were living longer

7 Firstly, of the likelihood of paid care vs. no care, and secondly of the likelihood of informal care vs. no care. change in provision will be necessary. It was examined whether the supply of informal and publicly funded home care has a different effect on the use of care among men and women. The relationship was studied between both the supply of home care - measured as public spending on home care - and informal care (the extent to which over-50s provide care), and the use of paid and informal care among older persons.

\section{The appropriate supply of care differs for men and women}

The first hypothesis was that higher public expenditure is associated with a lower likelihood of the use of informal care and care paid for by the user, and that this would particularly be the case among women. The results show that a more plentiful supply of care paid for through higher public expenditure is used by men in particular. For men, publicly funded care seems to be a substitute for informal care and for care paid for themselves. Among women, no significant association was found with informal care they received, and only paid care is used less often. It is possible that the higher age of the respondents plays a role here, meaning that the difference between men and women was other than what was predicted beforehand. In general, the higher the age, the more health problems an individual will have, and there comes a point when "not asking for help" is no longer a realistic 
option for that individual. Although care funded by the government could not be distinguished from care that users pay for themselves, the findings imply that most of the results reported here involved care paid for by the receiver. After all, if paid care mainly involved publicly funded care, some kind of positive association between the use and supply of paid care would have been found. Men generally have more money to spend than women and are more likely to be able to afford user-paid care, and this could also explain the fact that, among men, the association between the supply of publicly funded home care and the use of (user-) paid care is stronger than among women.

The second hypothesis is partly supported by the findings. The degree to which informal care is provided in a country is significantly correlated with (user-) paid care but is not related to receiving informal care. This applies to both men and women. A more plentiful supply of informal care is therefore not associated with more recipients of care, but with fewer recipients of paid care. The results of the model, therefore, suggest that the supply of informal care benefits those who are already receiving informal care and that it also acts as a substitute for paid care. The latter finding suggests that paid care is used mainly by individuals who have nobody in their social network who is willing or able to provide care.

This study has adopted a fairly rough and ready approach to the provision of publicly funded care and informal care. Data on the number of working professionals and the number of hours of care they provide would provide a more accurate estimate of the supply of care available. After all, higher spending on home care may also lead to qualitative improvements. However, such data is not currently available. In relation to the supply of informal care, too, a more detailed analysis of the amount of care provided would be preferable. The SHARE data includes information about the frequency of care, but not about how many hours of care are provided, for example. The care that is provided weekly is obviously less frequent than care provided daily, but if the daily care involves one hour per day and the weekly care involves eight hours per week, it is unclear which frequency might provide a greater benefit. There are opportunities for improvement in the individual measurement of the use of care. The SHARE data now includes the paid care that is received but does not distinguish between care paid for by the user and publicly-funded care. Earlier in this article, it was argued that these two forms of financing can act as substitutes for one another, but also for informal care. The negative relationship between the supply of publicly funded home care and user-paid care would probably have been stronger if it was possible to differentiate between these types of care empirically. Furthermore, migrants are over-represented in privatized care services in many European countries (DaRoit \& Weicht, 2013) which could lead to cultural differences in the care that is received. Although ideally it would be considered there was no information on migrant care available.

This study is based on data from different countries. Although it relates to Western countries that generally have reasonably good arrangements in place in relation to long-term care, the countries included also differ in many respects. The analyses were corrected for country differences by looking at changes over time in particular individuals, so that differences between individuals - and therefore between countries - play no role. Although the associations found in this study likely apply to all the countries studied, the extent to which they are applicable may vary. One recommendation for future research would therefore be to conduct an in-depth study into the role of differences in care provision and the use of care by men and women in the same country but in different regions.

\section{IImplications for policy and future research}

Although in the period 2004-2013 the number of older persons increased everywhere, the proportion of care users among them decreased. It decreased more among women than among men, mainly because the use of informal care among women fell more than it did among men. The demand for long-term care among men is likely to continue to increase. The results show that the supply of both informal care and expenditure on home 
care seems to have a stronger negative correlation with the use of (user-) paid care among men than among women. This would appear to lend further credence to the appeal that differences between men and women should be considered in the design of care systems, the supply of care products, the nature of the labor market in care, and the way in which it is funded (Morgan et al., 2016). The expectation was that the relationship between public spending on home care and the use of care, both informal care and (user-) paid care, would be stronger among women than among men, because women tend to experience a greater need for care and the threshold for requesting professional care seems to be lower among women. If the proportion of men among care users increases, a policy mismatch may develop (because women respond differently to men to changes in the supply of home care). The findings show that among men there is a stronger correlation between the use of care and the supply of both publicly funded home care and informal care than among women. Changes to care policy or to the financing and supply of care may therefore have a greater impact in the future, and lead to greater shifts in the use of care that have been observed hitherto. Although these effects found here are relatively small, it could possibly affect several million potential care users, amounting to billions of euros. It is important for policymakers to understand that investment in home care can have differing effects on men and women. Men appear to be more sensitive to changes in the provision of care than women, and among women, in particular, individual sources of care, such as a partner, play a more important role in the use of care.

\section{References}

Babitsch, B., Gohl, D., \& von Lengerke, T. (2012). Re-revisiting Andersen's behavioral model of health services use: A systematic review of studies from 1998-2011. GMS Psycho-Social-Medicine, 9(DOC 11). Crossref

Barker, J. C. (2002). Neighbors, friends, and other nonkin caregivers of community-living dependent elders. The Journals of Gerontology Series B: Psychological Sciences and Social Sciences, 57(3), 158167. Crossref
Beckfield, J. (2017). How social policy contributes to the distribution of population health: The case of gender health equity. Scandinavian Journal of Public Health, 46(1), 6-17. Crossref

Boerma, T., Hosseinpor, A. R., Verdes, E., \& Chatterji, S. (2016). A global assessment of the gender gap in self-reported health with survey data from 59 countries. BMC Public Health, 16(1), 675. Crossref

Bolin, K., Lindgren, B., \& Lundborg, P. (2008). Informal and formal care among single-living elderly in Europe. Health Economics, 17(3), 393-409. Crossref

Bond, J., Farrow, G., Gregson, B. A., Bamford, C., Buck, D., McNamee, P., \& Wright, K. (1999). Informal caregiving for frail older people at home and in longterm care institutions: Who are the key supporters? Health and Social Care in the Community, 7(6), 434444. Crossref

Börsch-Supan, A., Jürges, H., \& Lipps, O. (2003). SHARE: Building a panel survey on health, aging, and retirement in Europe. Mannheim: Mannheim Research Institute for the Economics of Aging (MEA).

Broese van Groenou, M., Glaser, K., Tomassini, C., \& Jacobs, T. (2006). Socio-economic status differences in older people's use of informal and formal help: A comparison of four European countries. Ageing and Society, 26(5), 745-766. Crossref

Bucher-Koenen, T., Lusardi, A., Alessie, R., \& Van Rooij, M. (2017). How financially literate are women? An overview and new Insights. J Consum Aff, 51, 255283. Crossref

Chamberlain, G. (1980). Analysis of covariance with qualitative data. The Review of Economic Studies, 47(1), 225-238. Crossref

Chiatti, C., Melchiorre, M. G., Di Rosa, M., Principi, A., Santini, S., D'Âhner, H., \& Lamura, G. (2013). Family networks and supports in older age. New York: Springer US. Crossref

Colombo, F., Llena-Nozal, A., Mercier, J., \& Tjadens, F. (2011). Help wanted? Providing and paying for longterm care. Paris: OECD Publishing. Crossref

DaRoit, B., \& Weicht, B. (2013). Migrant care work and care, migration and employment regimes: A fuzzyset analysis. Journal of European Social Policy, 23(5), 469-486. Crossref

Dorin, L., Krupa, E., Metzing, S., \& Beuscher, A. (2016). Gender disparities in German home-care arrange- 
ments. Scandinavian Journal Caring Science, 30, 164-174. Crossref

Enroth, L., Aaltonen, M., Raitanen, J., Nosraty, L., \& Jylhä, M. (2018). Does use of longterm care differ between occupational classes among the oldest old. European Journal of Ageing, 15(2), 143-153. Crossref

Gangl, M. (2010). Causal inference in sociological research. Annual Review of Sociology, 36, 21-47. Crossref

Gannon, B., \& Davin, B. (2010). Use of formal and informal care services among older people in Ireland and France. European Journal of Health Economics, 11(5), 499-511. Crossref

Glauber, R. (2017). Gender differences in spousal care across the later life course. Research on Aging, 39(8), 934-959. Crossref

Grabowski, D. C., Norton, E. C., \& Van Houtven, C. H. (2012). Informal care. Cheltenham, UK: Edward Elgar Publishing Limited.

Grundy, J., \& Jitlal, M. (2007). Socio-demographic variations in moves to institutional care 1991-2001: A record linkage study from England and Wales. Age Ageing, 36(4), 424-430. Crossref

Haberkern, K., Schmid, T., \& Szydlik, M. (2015). Gender differences in intergenerational care in European welfare states. Ageing and Society, 35(2), 298-320. Crossref

Hanaoka, C., \& Norton, E. C. (2008). Informal and formal care for elderly persons: How adult children's characteristics affect the use of formal care in Japan. Social Science and Medicine, 67(6), 10021008. Crossref

Hawkes, S. \& Buse, K. (2013). Gender and global health: evidence, policy, and inconvenient truths. Lancet, 381(9879), 1783-1787. Crossref

Hlebec, V., \& Filipovic Hrast, M. (2016). Influence of contextual and organizational factors on combining informal and formal care for older people. Slovenian case. Research on Ageing and Social Policy, 4(30). Crossref

Jacobs, M. T., Broese van Groenou, M. I., Aartsen, M. J., \& Deeg, D. J. H. (2018). Diversity in older adults' care networks: The added value of individual beliefs and social network proximity. J Gerontol B Psychol Sci Soc Sci, 73(2), 326-336. Crossref

Katz, S. J., Kabeto M., \& K. M., L. (2000). Gender disparities in the receipt of home care for elderly people with disability in the United States. Journal of the American Medical Association, 284(23), 3022-3027. Crossref

Kemp, G., \& Santos Silva, J. (2016). Partial effects in fixed-effects models. United Kingdom 2016: Stata Users' Group Meetings

Kemper, P. (1992). The use of formal and informal home care by the disabled elderly. Health Services Research, 27(4), 421-451.

Litwak, E. (1985). Helping the elderly: The complementary roles of informal networks and formal systems. New York: Guilford Press.

Luppa, M., Luck, T., Weyerer, S., König, H., Brähler, E., \& Riedel-Heller, S.G. (2010). Prediction of institutionalization in the elderly. A systematic review. Age Ageing, 39(1), 31-38. Crossref

Martikainen, P., Murphy, M., Metsä-Simola, N., Häkkinen, U., \& Moustgaard, H. (2012). Seven-year hospital and nursing home care use according to age and proximity to death: Variations by cause of death and socio-demographic position. J Epidemiol Community Health, 66(12), 1152-1158. Crossref

Mokken, R.J. (1971). A theory and procedure of scale analysis. The Hague/Berlin: Mouton/De Gruyter.

Morgan, R., George, A., Ssali, S., Hawkins, K., Molyneux, S., \& Theobald, S. (2016). How to do (or not to do)... gender analysis in health systems research. Health Policy and Planning, 31(8), 1069-1078. Crossref

Nieboer, A. P., Koolman, X., \& Stolk, E. A. (2010). Preferences for long-term care services: Willingness to pay estimates derived from a discrete choice experiment. Social Science \& Medicine, 70(9), 1317-1325. Crossref

Nihtilä, E., \& Martikainen, P. (2007). Household income and other socio-economic determinants of longterm institutional care among older adults in Finland. Population Studies, 61(3), 299-314. Crossref

OECD (2011). Divided we stand: Why inequality keeps rising. Paris: OECD Publishing.

Oudijk, D., Woittiez, I., \& de Boer, A. (2011). More family responsibility, more informal care? The effect of motivation on the giving of informal care by people aged over 50 in the Netherlands compared to other European countries. Health Policy, 101(3), 228-235. Crossref

Paternoster, R., Brame, R., Mazerolle, P., \& Piquero, A. (1998). Using the correct statistical test for the 
equality of regressing coefficients. Criminology, 36, 859-866. Crossref

Pattyn, E., Verhaeghe, M., \& Bracke, P. (2015). The gender gap in mental health service use. Soc Psychiatry Psychiatr Epidemiol, 50(1089). Crossref

Pforr, K. (2014). Femlogit-implementation of the multinomial logit model with fixed effects. The Stata Journal 14(4), 847-862. Crossref

Pickard, L., Wittenberg, R., Comas-Herrera, A., Davies, B., \& Darton, R. (2000). Relying on informal care in the new century? Informal care for elderly people in England to 2031. Ageing and Society, 20(6), 745772. Crossref

Pinquart, M., \& Sörensen, S. (2002). Older adults'preferences for informal, formal and mixed support for future care needs: A comparison of Germany and the United States. The International Journal of Aging and Human Development, 54(4), 291-314. Crossref

Plaisier, I., Verbeek-Oudijk, D., \& De Klerk, M. (2016). Developments in home-care use. Policy and changing community-based care use by independent community-dwelling adults in the Netherlands. Health Policy, 121(1). Crossref

Puthenparambil, M. J., Kröger, T., \& Van Aerschot, L. (2017). Users of home-care services in a Nordic welfare state under marketization: the rich, the poor and the sick. Health \& Social Care in the Community, 25, 54-64. Crossref

Roth, D. L., Fredman, L., \& Haley, W.E. (2015). Informal caregiving and its impact on health: A reappraisal from population-based studies. Gerontologist, 55(2), 309-319. Crossref

Saraceno, C., \& Keck, W. (2011). Towards an integrated approach for the analysis of gender equity in policies supporting paid work and care responsibilities. Demographic Research, 25(11), 371-406. Crossref

Schenk, N., Dykstra, P., Maas, I., \& Van Gaalen, R. (2014). Older adults' networks and public care receipt: Do partners and adult children substitute for unskilled public care? Ageing and Society, 34(10), 1711 . 1729. Crossref

Schmidt, A.E. (2018). Older persons' views on using cash-for-care allowances at the crossroads of gender, socio-economic status and care needs in $\mathrm{Vi}$ enna. Social Policy \& Administration, 52, 710-730. Crossref

Silverstein, M., Gans, D., \& Yang, F. M. (2006). Intergenerational support to aging parents: The role of norms and needs. Journal of Family Issues, 27(8), 1068-1084. Crossref

Suanet, B. \& Antonucci, T. C. (2017). Cohort differences in received social support in later life: The role of network type. The Journals of Gerontology: Series B, 72(4), 706-715. Crossref

Suanet, B., Broese Van Groenou, M., \& Van Tilburg, T. (2012). Informal and formal home-care use among older adults in Europe: can cross-national differences be explained by societal context and composition? Ageing and Society, 32(3), 491-515. Crossref

Suanet, B., Broese van Groenou, M., \& van Tilburg, T. (2017). Social network type and informal care use in later life: A comparison of three Dutch birth cohorts aged 75-84. Ageing \& Society, 0, 1-22. Crossref

Tarricone, R., \& Tsouros, A. D. (2008). Home care in Europe. The solid facts. Geneva, Switzerland: World Health Organization.

Triantafillou, J., Naiditch, M., Repkova, K., Stiehr, K., Carretero, S., Emilsson, T., Di Santo, P., Bednarik, R., Brichtova, L., Ceruzzi, F., Cordero, L., Mastroyiannakis, T., Ferrando, M., Mingot, K., Ritter, J., \& Vlantoni, D., (2011). Informal care in the long-term care system. Athens/Vienna.

Van Houtven, C. H., \& Norton, E. C. (2004). Informal care and health care use of older adults. $J$ Health Econ., 23(6), 1159-1180. Crossref

Verbeek-Oudijk, D., Woittiez, I., Eggink, E., \& Putman, L. (2014). Who cares in Europe. A comparison of long-term care for the over-50s in sixteen European countries. The Hague: Netherlands Institute for Social Research.

Verbrugge, L. M. (1985). Gender and health: An update on hypotheses and evidence. J Health Soc Behav, 26(3), 156-182. Crossref

Von Lengerke, T., Gohl, D., \& Babitsch, B. (2014). Re-revisiting the behavioral model of health care utilization by Andersen: A review on theoretical advances and perspectives. In C. Janssen, E. Swart, \& T. von Lengerke (Eds.), Health care utilization in Germany. New York: Springer. Crossref

Wang, H., Dwyer-Lindgren, L., Lofgren, K. T., Rajaratnam, J. K., Marcus, J. R., Levin-Rector, A., Levitz, C. E., Lopez, A. D., \& Murray, C. J. (2012). Age-specific and sex-specific mortality in 187 countries, 19702010: A systematic analysis for the global burden of disease study 2010. Lancet, 380(9859), 2071-2094. Crossref 